The University of Maine

DigitalCommons@UMaine

Publications

Senator George J. Mitchell Center for Sustainability

Solutions

$3-2016$

\title{
Transdisciplinary research partnerships in sustainability science: an examination of stakeholder participation preferences
}

Karen H. Beiluch

Dartmouth College

Kathleen P. Bell

University of Maine

Mario F. Teisl

University of Maine

Laura Lindenfeld

University of Maine

Jessica Leahy

University of Maine

See next page for additional authors

Follow this and additional works at: https://digitalcommons.library.umaine.edu/ mitchellcenter_pubs

Part of the Communication Commons, Economics Commons, and the Sustainability Commons

\section{Repository Citation}

Beiluch, Karen H.; Bell, Kathleen P.; Teisl, Mario F.; Lindenfeld, Laura; Leahy, Jessica; and Silka, Linda, "Transdisciplinary research partnerships in sustainability science: an examination of stakeholder participation preferences" (2016). Publications. 17.

https://digitalcommons.library.umaine.edu/mitchellcenter_pubs/17 
Authors

Karen H. Beiluch, Kathleen P. Bell, Mario F. Teisl, Laura Lindenfeld, Jessica Leahy, and Linda Silka 
Transdisciplinary research partnerships in sustainability science: an examination of stakeholder participation preferences

Karen Hutchins Bieluch ${ }^{1}$, Kathleen P. Bell ${ }^{2}$, Mario F. Teisl ${ }^{3}$, Laura A. Lindenfeld ${ }^{4}$, Jessica Leahy ${ }^{5}$, Linda Silka ${ }^{6}$

1 Environmental Studies Program, Dartmouth College, 6182 Steele Hall, Hanover, NH 03755, USA

2 School of Economics, University of Maine, 200 Winslow Hall, Orono, ME 04469, USA

3 School of Economics, University of Maine, 207 Winslow Hall, Orono, ME 04469, USA

4 Alan Alda Center for Communicating Science and School of Journalism, Stony Brook University, Melville

Library N4004, Stony Brook, NY 11794-3384, USA

5 School of Forest Resources, University of Maine, 241 Nutting Hall, Orono, ME 04469, USA

6 Senator George J. Mitchell Center for Sustainability Solutions, University of Maine, 5710 Norman Smith Hall, Orono, ME 04469, USA 
Abstract:

Sustaining coupled natural and human systems requires multiple forms of knowledge, experiences, values, and resources be brought into conversation to address sustainability challenges. Transdisciplinary research partnerships provide the opportunity to meet this requirement by bringing together interdisciplinary scientists with stakeholders in some or all stages of the knowledge production process. However, building partnerships to produce sustainability outcomes is a complex process requiring an understanding of the social psychological and contextual variables impacting partnerships. Here, we explore local government officials' (LGOs') preferences for participation in these partnerships. Using data from a statewide survey, we develop a theoretically and empirically derived model to test the relationship between a suite of factors and LGOs' preferred transdisciplinary partnership style. We find collaboration preferences are influenced by LGOs' confidence that researchers can help solve problems, experience with researchers, the severity and type of problem(s) occurring in the community, and partner trust. Assessing stakeholder partnership expectations may assist partners with co-designing flexible research processes that address collaboration expectations, foster dialog and social learning among project partners, and that increase the potential of research to influence change.

Keywords: Communication, Participation preferences, Collaboration, Social psychological variables, Sustainable solutions, Transdisciplinary research 
Introduction

To address sustainability challenges, multiple forms of knowledge, experiences, values, and resources need to be brought into conversation. Calls by sustainability science researchers assert that scientists must engage as active learners in knowledge co-production partnerships, rather than as external actors imparting knowledge (Kauffman and Arico 2014: 417). Recognizing the need to combine diverse knowledge sets and values to develop sustainable solutions, sustainability scientists, decision-makers, and citizens often attempt to work together in research partnerships (Polk 2014). Increased public pressure to engage directly with societal problems (Robinson 2008) and additional support from funding agencies for collaborative work (Reich and Reich 2006) also fuel these partnerships. Termed integrated research (van Kerkhoff 2008), collaborative university-community research (Nyden 2005) and transdisciplinary research (Cundill et al. 2005; Kauffman and Arico 2014; Polk 2014; Robinson 2008), among other names, these forms of collaborative research tend to be problem-focused, solutions-oriented and integrative in terms of interdisciplinary collaboration. Here we define transdisciplinary partnerships to mean partnerships that bring together interdisciplinary groups of scientists with non-academic actors (e.g. government agencies, industries, and non-profit organizations) to participate in problem- based partnerships. These actors contribute to some or all stages of the research production and solutions development processes (Kauffman 2014; Polk 2014). The power of such partnerships is great, but partners in transdisciplinary groups need to pay careful attention to research practices and interpersonal processes, as well as actual outcomes of the partnership, to ensure that partnerships function well and make progress on sustainability problems (Hutchins et al. 2013, Polk, 2014).

There are several frameworks available to examine transdisciplinary partnerships. Examples include Cash et al.'s (2006) framework for co-producing knowledge across boundaries between science and action, Lang et al.'s (2012) design principles for transdisciplinary research, van Kerkhoff's (2014) complexity principle-based approach for integrative research, and Barreteau et al.'s (2010) procedural framework for participatory research. While these frameworks are valuable for guiding partnership work in diverse contexts, we argue that the potential of frameworks to guide partnerships is enhanced when combined with an understanding of the social psychological and contextual factors that influence if and how stakeholders choose to engage in these partnerships. 
To extend the current literature on transdisciplinary partnerships, we developed a theoretically and empirically derived model that estimates the relationship among a suite of social psychological and contextual factors and stake- holders' preferred level of participation in transdisciplinary partnerships. The model provides insight on factors that influence stakeholder (here, local government officials-LGOs) participation preferences, and may be used as an assessment tool to help promote generative relationships.1 In our study site (Maine, USA), LGOs play a central role in decision-making processes and in implementing regulatory requirements impacting natural and human systems. Whether or not university researchers are working with LGOs in Maine, United States, as in this study, or farmers in the United Kingdom (Oliver et al. 2012) or water managers and owners in Switzerland (Schneider and Rist 2014), understanding and being mindful of collaborator engagement preferences and expectations is important for building the kind of partnerships that mobilize multiple forms of knowledge to address sustainability challenges.

Our study: (1) provides data on LGOs' preferences for participation in research collaborations and on factors influencing their preferences; (2) reveals opportunities for strengthening communication among project partners using the model as a communication tool to improve "social interactions and processes between actors" (Reed et al. 2010: 1); and (3) recommends how to use this type of process and data to address on-the-ground conditions that impact engagement in partnerships. In fact, one impetus for this study was to better understand a key stakeholder group involved in transdisciplinary research being conducted by an interdisciplinary group of researchers engaged in a large, sustainability-focused National Science Foundation (NSF)-funded initiative. The survey findings assisted some researchers with understanding and approaching LGOs, and with their collaboration strategies generally.

Literature review: stakeholder-engaged research and social psychological and contextual variables

Transdisciplinary partnerships are important for advancing certain sustainability outcomes, such as social learning (Schusler et al. 2003), understanding of problem complexity (Gonzalo-Turpin et al. 2008), augmented and enriched science (Prober et al. 2011), and strengthened links between knowledge and action through improved 
research saliency (Kueffer et al. 2012), legitimacy, and credibility (Cash et al. 2003). Outcomes generated through transdisciplinary research and collaborative management, such as knowledge that is co-produced and expanded social networks among diverse actors in the system (Tompkins and Adger 2004), and project ownership (Stauffacher et al. 2008), help build the capacity necessary to link research and planning with sustainability outcomes (Folke et al. 2002; Walter et al. 2007; Matson 2009; Hart and Calhoun 2010; Kueffer et al. 2012; Wiek et al. 2012). However, establishing transdisciplinary partnerships and ensuring that they produce sustainability outcomes (Muñoz-Erickson et al. 2010) is a complex process that is not guaranteed to succeed. As Leeuw et al. (2012) and Wiek et al. (2012) discuss, one of the complicating factors is that academics often lack experience with conducting participatory transdisciplinary research. Therefore, they may attempt to develop partner- ships without investing in important preparations that could enhance the success of the collaboration.

A second challenge in transdisciplinary research is managing the boundaries between science and policy. As Guston (2001) discusses, some parties involved at these boundaries express concerns with the scientization of politics and the politicization of science. Boundary organizations, organizations that involve parties from multiple sides of an issue and are accountable to all parties involved in the process, that are responsive to both parties' best interests can play critical roles in managing and negotiating this boundary. One of the critical roles boundary organizations can play in transdisciplinary partnerships is to help each side identify, articulate, and assert their expertise, needs, roles, and vision of how the efforts align with their goals (Guston 1999). Crona and Parker (2012) found that bridging organizations, a type of boundary organization, help address issues of alignment between partners by creating a "depoliticized arena" (p. 10) in which academic and policy stakeholders can align interests, increase social interactions between participants, and expand social networks.

Finally, a third challenge is that the processes needed to conduct transdisciplinary research change with changes to the issue under investigation, the context, and the individual and institutional partners involved (Shirk et al. 2012). For example, in some research partnerships stakeholders are involved in communication about completed research, while at other times, researchers collaborate with stakeholders throughout the entire research process, starting with problem identification. While engaging stakeholders at all stages of the research process may seem ideal for encouraging learning throughout the process, that model of engagement may not work for all participants 
(Barreteau et al. 2010). Indeed, pursuing a goal of full collaboration without allowing partners con- trol over the collaboration process may discourage participation and limit partnership potential by including only those individuals who are able and want to collaborate fully (Peterson 2010). Instead of developing a single participatory model that can be emulated across research partnerships, transdisciplinary partnerships benefit from thinking flexibly, creatively, and realistically about the level of scientist and stakeholder participation in different stages of the partnership. Flexibility is necessary because partnership design ultimately must be responsive to con- text, group goals, the different stages of the research process (Stauffacher et al. 2008), and individual participant preferences.

Research on transdisciplinary research and collaborative resource management indicates that numerous individual social psychological and contextual variables influence stakeholder behavior in research partnerships, ranging from individual demographic characteristics (e.g. socioeconomic status) to cultural differences (e.g. practices, knowledge forms, and traditions) to institutional characteristics (e.g. the ability to resolve conflict, institutional reward structure) to collaboration design (e.g. guiding documents that outline task, responsibilities, and principles of collaboration) (Leeuw et al. 2012; Silka et al. 2008). Of particular interest in this study are variables that influence the extent to which stakeholders prefer to participate in research partnerships. Importantly, these variables, among others, impact- positively and negatively- the capacity pf transdisciplinary research partnerships to fulfill the goals of sustainability science. Below we discuss four categories of factors that have been documented to influence engagement in collaborative work and decision-making. We hypothesize that these factors also influence the extent to which stakeholders prefer to participate in research partnerships.

Beliefs about partnership helpfulness and helpfulness of other partners

Given the extensive amount of time that collaborative work requires of participants, a prospective collaborator's preferences for participation may be influenced by the extent to which he/she believes the partnership will help solve the problems being addressed. For example, if the participant does not believe the partnership will be helpful, it is unlikely she/he will prefer highly collaborative partnerships. In contrast, if prospective research collaborators 
believe that other organizations may be able to help them solve problems, they may desire more highly collaborative research partnerships to ensure that other collaborators are involved or that their opinions are represented at various stages of the research process. Although people have studied belief in the helpfulness of a partnership in relation to willingness to engage in partnerships (Lubell 2004; Pettersson et al. 2009), there is a lack of research on the relationship between this variable and one's preferred level of collaboration. In this study, we assessed LGOs' belief that university researchers may help them resolve local management issues and their belief that other, non-academic organizations may help them resolve local management issues.

Perceived costs and benefits of collaboration

Research findings indicate that stakeholder cooperation in partnerships is influenced by cost-benefit perceptions. The benefits of collaboration must outweigh or be equal to the costs to motivate cooperation among partners (Lubell 2005; Barreteau et al. 2010).

Lubell (2007) found that institutional distance, which is partly influenced by physical distance, between individuals and agencies influences trust; increased distance leads to fewer interactions leading to decreased trust. In addition, there are very real transaction costs associated with travel. Hence, we analyze how LGOs' physical proximity to the nearest university influences LGOs' interest in developing transdisciplinary partnerships.

Larger institutions are more likely to have greater human resources to engage in partnerships because one employee investing time in a partnership is less costly for a larger organization. Thus, we use municipality population size as a proxy variable for institutional size because population size tends to be positively correlated with the number of LGOs working within a community.

Experience with a person or institution reduces uncertainty because more is known about the situation (Thornton and Leahy 2012) and other actors' behavior (Lubell 2005). In other words, a reduction in uncertainty may mean a reduction in the associated costs of interacting with an unknown partner. Further, experience tells us many things about a relationship, such as if it is productive, if we get along well with others involved, if we 
perform well, or if we can fit the relationship into our schedules. At a basic level, experience helps us assess the costs and benefits of an experience, or in this study, a collaboration (Lubell 2005). Despite the benefits associated with a reduction in uncertainty, the costs of unpleasant past experiences may outweigh the benefits. For example, people with negative past experiences may calculate the costs associated with partnerships as outweighing the benefits of investing in the collaboration and, therefore, may prefer less collaborative partnerships. In this study, we asked participants if they had prior experience working with college or university researchers, as a measure of (un)certainty.

Perceptions of problem severity and type

The literature on the relationship between perceptions of problem significance and type and preferred level of participation in a partnership is sparse. However, prior research related to participation generally reveals that people who perceive a problem as severe are more likely to join a partnership that addresses the issue of concern than people who do not perceive that a problem exists (Lubell et al. 2002). Further, Höppner et al. (2007) discovered individuals' intentions to participate in landscape planning and their preferred form of participation were influenced by their perceived self-competence on the issue, suggesting the type of problem addressed influences the way people engage in partnerships. Here we evaluated four categories of issues, economic, social, environmental, and policy problems, and the severity of the problems in local com- munities and tested their impact on LGOs' interest in developing a research partnership.

Trust

Trust is a complex variable that impacts preferred levels of participation in collaborative processes in sometimes counter-intuitive ways. For example, research on public participation in policy-making indicates that when stake- holders have high overall trust in officials presiding over the policy-making process and in fellow stakeholders participating in the process, they prefer lower levels of involvement. In contrast, if they distrust officials and fellow stakeholders, they prefer higher levels of participation (Focht and Trachtenberg 2005; Smith et 
al. 2013a, b), allowing for increased monitoring and opportunities for input. Interestingly, Focht and Trachtenberg (2005) found that stakeholders base their trust evaluations on different factors, instead of having one singular evaluation of trust. For example, they found that value similarity was important to stakeholders when determining trust in public officials and fellow stakeholders, whereas technical competence was central to evaluating trust in experts. Studying community-water resource management agency relationships with qualitative methods, Leahy and Anderson (2008) discovered five major factors comprising overall trust, including trust in the governing agency, social trust in people in general, trust in the technical competence of the governing agency, trust in shared interests among members of the partnership, and trust related to feelings of being heard and having influence.

These factors were validated in subsequent quantitative work (Smith et al. 2013a, b). In light of this complexity, it is appropriate to measure "trust-warranting properties," (Lubell 2007: 245), such as fairness, technical expertise, and shared interests (Focht and Trachtenberg 2005; Leahy and Anderson 2008), in addition to generalized trust. In this study, we assessed stakeholders' overall trust in and trust-warranting proper- ties (i.e., technical expertise and shared interests or values) of university researchers.

Conceptual model

Based on our review of the literature, we developed a conceptual model of the relationship among a set of factors and stakeholders' preferred participation strategies in community-engaged research partnerships (see Fig. 1).

Prior research on stakeholder engagement in scientific research and the public's participation in environmental decision-making (e.g. Bell et al. 2013; Focht and Trachtenberg 2005; Hutchins et al. 2013; Leahy and Lindenfeld 2013; Lyons et al. 2014) informed the development of four broad strategies for stakeholder and researcher participation in transdisciplinary research processes: lead, consulting, facilitating and full. The strategies vary by researcher and stakeholder involvement in four general stages of the research process. We view the navigation of problem identification, research, proposed solutions, and implementation of solutions stages as critical to transdisciplinary research partnerships. Further, we conjectured that a stakeholder's assessment of the utility, or usefulness, of different participation strategies is influenced by a combination of factors, including confidence in or a belief about the helpfulness of university researchers in solving municipality problems, 
confidence in or a belief about the helpfulness of other organizations in solving municipality problems, perceived costs and benefits of collaboration, characteristics of the problem, such as problem significance and type, overall trust in project partners and agreement with trust-warranting properties of project partners.

Materials and methods

To test our conceptual model of transdisciplinary research partnerships, we asked LGOs to express their preferences for four strategies of participation in hypothetical collaborative research partnerships with university researchers, and then used a discrete regression model to explain the variation in preferred strategies as a function of predictor variables representing the key explanatory factors in our conceptual model. We assessed LGOs because of their decision-making role in sustainability-related issues in Maine (e.g. climate change mitigation, vernal pool regulation, waste management strategies, storm water management, community development, etc.) and the importance of their involvement in research projects being conducted by researchers involved in a large statewide sustainability-related research initiative carried out in Maine, United States.

Study area

The state of Maine in the northeastern United States, the study area of this empirical research, provided a quality location to examine transdisciplinary research partnerships. Maine's history of strong local control, local government decision-making capacity, and numerous and diverse municipalities elevates the relevancy of municipal officials, such as town and city managers and select board chairs, to address place-based sustainability challenges. The need to evaluate the role of local scale management in addressing sustainability issues is documented in the literature (McLarty et al. 2014; Polk 2014). Further, Maine's universities and colleges are diverse in size and mission, and they generally share a common interest in establishing research partnerships with stakeholders. The variation in both communities and universities created an institution- ally diverse setting in which to conduct our study. Finally, LGOs are a critical group to reach and understand how to engage within the sustainability-related, transdisciplinary research initiative that our study focused on (McGreavy et al. 2015). 
Respondents and procedures

Our sampling frame consisted of lead municipal officials, such as the fire chief and welfare director, occupying positions serving the following functions, as defined by the Maine Municipal Association (MMA), a non-profit organization serving Maine municipalities and local government agencies: key official, community development, planning, purchasing, assessing, finance, public safety, recreation, chief elected official (e.g. select board or planning board chairperson), personnel, public works, welfare, and code enforcement. We purchased the list of LGOs from MMA. Their mailing list is updated daily (Label Request Form (2016)). We included in the sample one person from each function area in each municipality in Maine; only a few municipalities had all 13 positions. Officials in each of these positions are likely to be involved, at some level, with issues related to sustainability, whether it be in a decision-making, enforcing, or enacting role. Regardless of the role, individuals in each position have the potential to be critical players in trans- disciplinary partnerships. We distributed the Maine Municipal Official Survey to 2553 municipal officials.

Using a modified version of the Tailored Design Method (Dillman et al. 2009), we sent four solicitations for participation, including a pre-notification letter, first-round survey and invitation letter, reminder postcard, and second- round survey and invitation letter. We achieved a $46 \%$ response rate $(N=1177)$, and respondents represented $86 \%$ of Maine municipalities. Our analysis is based on a subset of these respondents $(n=596)$ due to missing data. The majority of observations were lost due to missing data on the dependent variable (321 obs.), the problem severity variables (136 obs.), and the trust statement variables (trust in technical knowledge, 115 obs.; trust in shared values, 109 obs.). Descriptive results (not shown) for the subset and the full dataset were similar (i.e., means of 11 of the 16 independent variables are within $1 \%$ deviation, 2 within $3 \%$ deviation, 1 within 5\% deviation, and 2 within $7 \%$ deviation).

Survey design

The survey instrument consisted of three sections ("Appendix A”). Section one asked about general 
municipal official and municipality background information. Section two solicited information about current and future economic, social, environmental, and policy problems in the individual municipalities. To develop the set of issues included in the survey, we drew on the format of the National League of Cities survey of local government officials, a survey that scopes out problems of national significance in the United States. To tailor the survey to fit Maine, we gathered feedback from state policy makers, municipal organizations, media analyses, and ongoing or proposed research projects involved in our sustainability- related research program.

In section three, respondents were asked about their prior work with university researchers, their trust in research, and their interest in participating in future municipality-university partnerships. They were also presented with four participation strategies with different roles for LGOs and university researchers at each stage of the research process (Table 1). They were then asked to select their 'most preferred' strategy; response to this question is used as the model's dependent variable. Because we were asking about a hypothetical partnership, it was important to provide context to help LGOs think about a potential research relationship. We used three tactics, including the pre-notification letter, the questions that preceded the question, and the description of partnerships within the question. The pre-notification letter explained the research project and how we were hoping to use the survey data to inform the development of community-university partner- ships. The pre-notification letter included the following statement:

One of our team's research goals is to increase the relevance and responsiveness of university research to Maine communities, to address the economic, social, and environmental issues that our state faces. To help reach this goal, our team designed a survey aimed at understanding the problems facing Maine municipalities and your municipality's interest in and preferences for partnering with Maine universities to help manage these problems. We believe that this survey is an important first step toward understanding how municipalities, like yours, and Maine universities can work together.

Questions preceding the partnership strategy question asked respondents to think about their experience with university researchers, if any, as well as their trust in university researchers. We designed this sequence of 
questions to elicit well thought-out responses by clumping questions of similar topics together (Dillman et al. 2014), and we strategically ordered the questions to move respondents from answering questions about their immediate experiences to considering hypothetical situations. Finally, we provided the following explanation prior to asking people to assess the four participation strategies,

Community-university partnerships are structured in many ways. We are interested in your opinion about four alternative strategies for community-university partnerships. The alternatives differ according to how municipalities and university researchers share responsibilities.

These tactics provided context to help respondents think about potential partnerships and select their preferred participation strategy.

Empirical analysis

Employing local officials' survey responses, we empirically operationalized the previously outlined conceptual model using discrete choice regression analysis to assess stakeholders' stated participation strategy preference. We conceptualized this regression using a random utility modeling approach. Local officials hold different perceptions of the returns (i.e., utility) from different participation strategies $\left(U_{s}\right)$; variation in these perceptions can be partially explained by identified key factors $(X)$; and the most preferred participation strategy of local officials generates the highest perceived return. Building on these assumptions and acknowledging researcher and decision-making uncertainties, we delineated a discrete choice model of strategy choices. Formally and following Greene (2003), we can represent the utility of selecting a particular strategy, $j$, for local official $i$ as:

$U_{i j}=X_{i}^{\prime} \beta_{j}+\varepsilon_{i j}$

where $U_{i j}$ represents the return or utility from strategy $j$ to local official $i, X_{i}$ is a vector of our measures of key factors for official $I, \beta_{j}$ is a vector of parameters to be estimated, and $\varepsilon_{\mathrm{ij}}$ is a random error term (assumed here to be independent and identically distributed type I extreme value (Gumbel)). The discrete choice model builds on this expression and describes the probability that strategy $j$ is chosen over other strategies as a function of the relative 
utilities $\left(\operatorname{Prob}\left(U_{i j}>U_{i k}\right)\right.$ for all other $k=j$ in the set of strategies presented to the local officials. Given that officials selected their most preferred strategy, we can summarize the empirical model as follows:

$\operatorname{Prob}\left(Y_{i}=j\right)=\frac{e^{\beta_{j}^{\prime} x_{i}}}{\sum_{k=1}^{4} \beta_{k}^{\prime} x_{i}}, j=1,2,3$

Dependent variable

Most preferred participation strategy. We asked respondents to choose their most preferred participation strategy: lead (lead), consulting (consulting), facilitating (facilitate) or full (full); however, we dropped lead from the model because only 14 respondents chose this strategy. The three remaining strategies only vary across three (research, proposed solutions, and implementation) of the four stages of the research process (i.e., problem identification is constant across the three strategies). Hence, the difference between consult and facilitate is that LGOs become involved in developing solutions, and between facilitate and full, LGOs become involved in the research while university researchers become involved in solution implementation. Thirty-seven percent of respondents preferred the consulting strategy, $38 \%$ preferred the facilitating strategy, and $25 \%$ preferred the full collaboration strategy (Table 2).

Independent variables

Beliefs about partnership helpfulness and helpfulness of other partners. We invited respondents to report their belief about partnership helpfulness by asking them to describe how much, if at all, researchers may be of assistance in resolving municipality problems and how much, if at all, other organizations may be of assistance in resolving municipality problems. We measured beliefs about university partners' helpfulness and other partners' helpful- ness using a categorical variable with three options: yes, no, and not sure.

Perceived costs and benefits of collaboration. Costs and benefits were calculated using three different variables, including institutional proximity, municipality size, and experience. We calculated distances from all municipalities in our sample to all New England Association of Schools and Colleges (NEASC) accredited 
universities and colleges in Maine. Institutions accredited by NEASC have physical campuses or offices and share basic standards of education, even though the curriculum varies by institution. We included distance in the model as a continuous variable. We determined population size using the U.S. Census 2010 full-time resident data and included it as a continuous variable in the model. We measured prior experience using a categorical variable with the following options: yes, no, and not sure.

Perceptions of problem severity. To measure the perceived severity of different types of problems, we presented respondents with 10-13 problems for each of four types of problems: economic, social, environmental, and policy. We asked respondents to rate each problem statement on a four-point scale (for economic, social and environmental problems): not a problem, small problem, moderate problem, serious problem; for policy problems: no debate, limited debate, moderate debate, extensive debate. We excluded responses of not sure and not applicable. For each problem type we created an index by averaging each individual's responses. Reliability tests indicate each index is highly reliable: economic $(\alpha=0.80)$, social $(\alpha=0.84)$, environmental $(\alpha=0.90)$ and policy problems $(\alpha=0.78)$. We cite Allen and Seaman (2007) to justify treating the index as continuous based on high reliability alpha scores for the four problem indices.

Trust. To measure officials' trust, we measured overall trust in one question using a five-point scale: not at all, a little, not sure, some, and a lot. Given few respondents stated not at all (12 obs.), a little (29 obs.), or not sure (148 obs.), we collapsed these three categories into our baseline level of trust we titled low trust. We measured respondents' level of agreement on a series of trust statements related to perceived researcher shared interests/values and expertise on a five-point scale: strongly disagree, somewhat disagree, neither disagree nor agree, somewhat agree, and strongly agree. To build an index that measures respondents' trust in researcher shared interest/values, we calculated the mean score across three statements, such as "I trust researchers (faculty/staff) from the University of Maine System because they care about my community" $(\alpha=0.78)$. To build an index that measures respondents' trust in researcher knowledge, we calculated the mean score across five statements, such as "I trust researchers (faculty/staff) from the University of Maine System because they provide unbiased information" $(\alpha=0.89)$. 
Results

We used statistical analysis system (SAS) software to estimate the discrete choice model using maximum likelihood. The models comparing choices consulting (consulting), facilitate (facilitating) and full (full) converged in five iterations. The model fit was significant $X_{d f}=34=95.32, p<0.001$. Multicollinearity diagnostic results were normal, with tolerance scores greater than 0.20 and variance inflation factor (VIF) scores below four (Vaske 2008). We ran the Hausman test for the independence of irrelevant alternatives. The test indicated that when we dropped the consulting choice, $X_{(17)}^{2}=15.02, p=0.99$. When we dropped the facilitate choice, $X_{(17)}^{2}=0, p=1.00$, and when we dropped the full choice, $X_{(17)}^{2}=0, p=1.00$. These results demonstrated that when we run the model with one of the alternatives dropped, the remaining (restricted) model is not statistically different from the full model (SAS Institute, Inc. 2012). Positive (negative) coefficients indicated a positive (negative) relationship between the independent variable and the reference strategy of consult.

Due to the numerous interaction terms, we illustrate the effects of the independent variables on choice by predicting different outcomes across different variable scenarios (Figs. 2, 3, 4, 5, 6).

Experience and the beliefs about the helpfulness of university researchers

LGOs without research partner experience but who believe researchers can help resolve municipality problems (first bar in Fig. 2) are more likely to prefer full participation strategies (i.e., university and LGOs share responsibility over all stages of the research process) over consulting or facilitating strategies. Inexperienced LGOs who are uncertain if researchers would be helpful (second bar, Fig. 2) have a similar ranking of strategy preferences but are now more (less) likely to prefer consulting or facilitating (full) strategies.

LGOs with experience who believe researchers can help solve problems (third bar, Fig. 2) prefer full over facilitating strategies, and facilitating over a consulting strategy. Comparing this group with those who lack experience (first bar) indicates that experience increases the relative preference for the facilitating strategy. 
Experienced LGOs who are uncertain if researchers are helpful (fourth bar) were similar to their inexperienced counterparts (second bar) indicating that experience has no impact if there is uncertainty around a researcher's helpfulness. Experienced LGOs who did not believe researchers are helpful (fifth bar) preferred a consulting over a facilitating over a full strategy. Finally, comparing the first and second bar, and the third to fifth bars, indicate that decreased perceptions of helpfulness increases the preference for a consulting or facilitating strategy and a decreases preferences for full participation. This suggests that LGOs are less interested in interacting with researchers they perceive as unhelpful.

Beliefs about the helpfulness of other partners

Relative to Fig. 2, differences in the beliefs about the helpfulness of others did not generate as large effects in the relative preferences for partnership strategies with university researchers (Fig. 3). As we would expect, as others are perceived to be less helpful, LGOs have an increasing preference for full partnerships with university researchers and generally lower preferences for facilitating and consulting strategies. That is, as others become less suit- able substitutes for university researchers, the value of increased engagement with researchers increases.

Perceived costs and benefits of collaboration: municipality characteristics

A municipality's population size, and the distance from a Maine university or college did not impact LGOs' preferences for consulting, facilitating, or full participation strategies (see “Appendix B',; no figure is presented).

Perceptions of problem significance and problem type

When we compare the issues not a problem (first bar, Fig. 4) result, which assumes all issues or problems are not a problem, to the other results (second through fifth bars) which assumes only one issue or problem is a severe problem, we find that LGOs' preferences for participation strategies were significantly impacted by problem severity, except with respect to environmental problems. That is, the distribution of preferences for strategies when 
environ- mental problems are severe (third bar) are similar to having no severe issues (first bar). Interestingly, the perception of severe economic (second bar) or policy (fifth bar) problems increases the preference for a facilitating strategy and decreases the preference for a consulting strategy (relative to the first bar) while a severe social problem (fourth bar) leads to an increased (decreased) preference for a consulting (facilitation) strategy. Apparently, LGOs want to reduce their involvement in proposing potential solutions to social problems, but want to be more involved in proposing potential economic or policy solutions.

Trust

LGOs who stated they trust university researcher a lot (second bar, Fig. 5) were more likely to prefer a facilitating rather than consulting strategy, compared to those who do not trust researchers (first bar, Fig. 5). We also found what LGOs trust about researchers matters to their choice of participation strategy. When there is little trust in researchers' values or knowledge (first bar, Fig. 6), officials are indifferent between strategies. However, those who trusted researchers because of their knowledge slightly preferred a facilitating strategy over a consulting or full strategy (third bar), while those who trusted researchers because of shared values preferred a consulting strategy over the other strategies. That is, when LGOs think university researchers share their values, the officials are less likely to want to be involved in proposing solutions.

\section{Discussion}

Our model highlighted a set of social psychological and contextual variables that impacted participation strategy preferences in transdisciplinary research partnerships; the model findings extend, complicate, and support prior research. First, the findings offer new insights on the impact of the interactions between LGO's experience with university researchers, and their belief in the helpfulness of those researchers, on their participation preferences. While experience has been studied in relation to willingness to participate (Lubell 2004), there is a paucity of data on the relationship between this variable and participation preferences. This finding extends research by Thornton and Leahy (2012) by demonstrating that reducing uncertainty (lowering costs because 
uncertainty is costly) through experience does not necessarily reduce the total perceived costs of the partnership. Our study demonstrates that beliefs about helpfulness significantly influence partnership preferences and suggests that scientists interested in engaging stakeholders in the research process evaluate this prior to, and during, the collaboration. One should not just assume that stakeholders think researchers will be useful problem-solving participants.

Second, results of the analysis in relation to the costs and benefits of collaborations extend prior research. The non-significant relationship between institutional proximity and participation preferences suggests that additional research is needed on proximity, as prior research documents that this variable impacts stakeholders' evaluations of project partners (Hutchins et al. 2013, Lubell 2007).

Third, similar to research conducted by Hutchins et al. 2013 and Lubell et al. (2002), we find the impact of problem severity on participation preferences is influenced by the type of problem. Here economic and policy problems had one effect while social problems had an opposite effect and environmental problems had no impact on preferred partnership strategy. These findings indicate that not all problems and partnerships are created equal. In addition, stakeholder engagement preferences are likely influenced by individuals' expertise and job responsibilities (variables not tested in this study). For example, a municipal official with expertise in code enforcement may not feel qualified to participate in a research partnership focused on poverty reduction, and thus, may prefer to assume a less collaborative, more peripheral role in the partnership. Similarly, if an official is in charge of health and human services for a community, s/he may not have the time or support from bosses to engage in a highly collaborative partnership focused on establishing new building codes. These constraints may influence stake- holder engagement preferences. When conducting solutions-orientated sustainability science research, researchers will likely have to engage with a variety of constituents who have knowledge about, interest in, and influence on the issues being addressed through the research. LGOs with various responsibilities may play unexpected roles in the research-solution process. Stakeholders and university researchers involved in an ongoing partnership may benefit from reassessing their preferences as the problems being explored in the partnership evolve. 
Finally, the results related to trust are somewhat similar to Focht's and Trachtenberg's (2005) findings where they found that higher levels of trust in fellow participants resulted in a desire for less collaborative processes (i.e., there was a lower need to work with/monitor partners). We have three trust measures and one of the three measures is consistent with Focht and Trachtenberg; LGOs who perceived higher levels of shared values between themselves and researchers preferred less collaborative strategies. The reverse relationship occurs with the other two trust measures. Thus, we find that, similar to Focht and Trachtenberg, stakeholders base their trust evaluations on different factors; values-based trust and knowledge-based trust have different effects. This suggests that the impact of trust on relationships is not unidimensional. Future research should explore interactions between trust and mediating or moderating variables, such as the level of control over partnership outcomes. For example, in government-citizen interactions, such as those studied by Focht and Trachtenberg, the government has a higher level of control over the decision-making process than citizens. In research partnerships, researchers may have a higher level of control over the research process than collaborators, but collaborators are likely to have a higher level of control over implementation of the research than researchers.

Importantly, when considering the impacts of these variables on participation preferences, one must keep in mind that each parameter shows a marginal impact on the dependent variable, holding everything else constant. In reality, it is likely that these variables impact partnership preferences in nuanced ways. For example, although a community partner who has experience with researchers and believes they may help solve local problems may prefer a more versus less collaborative partnership, the partner's collaboration preference may vary depending on the type of problem being addressed in the partnership (e.g. a social versus policy problem). Thus, it is important to contemplate the effects of these variables when they are simultaneously in play in the partnership.

In addition to offering a set of social psychological and contextual variables to consider when assessing stakeholder engagement preferences in partnerships, we offer the model as a tool for assessing and informing partner alignment and reciprocal communication. Asking stakeholders about their participation preferences and expectations (Wiek et al. 2012) provides valuable data on (mis)alignment with team member preferences and establishes a communication space that encourages shared decision-making and open, mutual information 
exchange. As Barreteau et al. (2010) argue, procedural communication that explicitly addresses partnership design and encourages feedback from stakeholders on that design may be "essential for effective communication" (17). Communication is strengthened when there are opportunities for partners to discuss their expectations of each other and their partnership goals, and to negotiate how they want to work together. Partnerships that are well aligned and encourage reciprocal communication also open the space for social learning in partnerships addressing complex sustainability issues because they encourage interactions where participants share and explore ideas that may, ultimately, influence the way participants see and interact in the world (Reed et al. 2010).

\section{Conclusion}

Given the messy and dynamic nature of the issues being addressed in sustainability science, transdisciplinary partnerships required to study and develop solutions for these systems are likely to be complex. In recognition of this complexity, the model here is best viewed as a tool (Shirk et al. 2012) for improving participatory research design and team member alignment and communication. The model needs to be adapted to the context and language of local conditions (Shirk et al. 2012). The importance of adapting the model to specific projects and local conditions was highlighted during discussions of our study findings with our colleagues on other teams that were part of the sustainability-focused research initiative. The findings helped teams understand LGOs and the social-ecological context in which they were working, which helped frame their communication with them. However, teams found factors not accounted for in the model, such as stakeholders' confidence in participating in the research process or the researchers' capacity to engage in highly collaborative partnerships. Teams explained that these factors further complicated decisions about how to work with each other.

The survey and developed model may also be used as learning tools to understand and work with project partners. If partnerships are analyzed only at the beginning and end, as is often the inclination, one may miss critical aspects of the evolving relationship that provide opportunities to intervene by changing relationship patterns that result in more adaptive or resilient relationships. Following van Kerkhoff (2014), we encourage researchers to take a learning orientation to transdisciplinary partnerships by using and adapting this model as a tool to help partners learn about each other and provide insight on partnership emergence. A learning orientation 
implies that the language used in approaching and designing the research process encourages ongoing learning among partners. Using bridging organizations to help facilitate these partnerships may assist these groups with aligning interests, growing social networks, and creating a "depoliticized" social environment that is necessary for the integration of knowledge with research (Crona and Parker 2012). The potential of the survey data and model to inform partner- ship design and function was documented on one of the project teams involved in the sustainability-focused research initiative.

This project team collaborated with a non-profit made up of a group of stakeholders working together to promote sustainability in a particular ocean bay in Maine. During the early stages of this collaboration, we provided the group a summary report of survey responses from LGOs in municipalities surrounding the bay, and we also met with them to discuss how the lessons learned from survey data may help promote successful collaboration among stake- holders. When asked how the survey influenced their work, one of the researchers explained that the report informed their understanding of which issues were important to municipal partners, how to frame the team's work to demonstrate alignment with municipal interests, and it assisted them with their outreach to municipalities. The second and less tangible way the work assisted the team was to inform their understanding of the value of communication research for creating diverse and resilient sustainability partnerships. The technical report and discussions about the survey data helped the team under- stand that there are many forms of expertise, all of which need to be considered in the context of these complex issues. In other words, the survey findings and approach promoted learning among project partners, and it influenced their practices by revealing the importance of approaching collaboration with a commitment to learning from each other and valuing the diverse knowledge at the table.

There are several limitations to the study and opportunities for future research. First, the variability in who does what during different stages of the research partnership is limited in this study (i.e., it is not an experiment). For example, researchers are involved in all stages of the research process, except for implementation, in each choice option. We selected this design because researchers were required, as part of the grant under which we conducted this work, to be part of these research stages. However, future studies could use experimental design 
approaches to provide a richer data set. Further, future researchers may wish to add additional stages to the research process (e.g. data gathering and data analysis) instead of the broad category research, as research demonstrates this variability in participation exists (Lang et al. 2012). Second, a stakeholder may select a less collaborative form of participation because he/she does not believe the researcher can really help solve the problem under investigation. Understanding stakeholder beliefs is important, but understanding the underlying cause or preconditions of the beliefs is equally important. Future studies could explore the development of beliefs over the life of the partnership (see Höppner et al. 2007) so those preconditions can be addressed and potentially altered to encourage participation. Third, Höppner et al. (2007) documented that respondents' intention to participate in a planning process was impacted by their perceived self-competence or their perception of whether they have the content knowledge necessary to contribute to the process. Thus, it is reason- able that future research on partnerships may want to explore perceived self-efficacy and competence in participatory endeavors.

The act of assessment is central to the process of participatory research, as it assists in identifying alignment between partners, demonstrates shared power over the research process, and lays the foundation for dialog, and reciprocal communication, about process and collaboration throughout the partnership. While prior researchers identified design principles for transdisciplinary partnerships in sustainability science (Lang et al. 2012), offered a frame- work for organizing partner communication about participatory research processes (Barreteau et al. 2010), and provided principles for engaging in community-based research (Israel et al. 1998), there is a lack of research on factors that influence how stakeholders prefer to engage in the research process. Our research begins to fill this gap and argues that such assessments may help promote alignment and open communication in the partnership, as well as complement the valuable frameworks previously proposed in the literature.

If we aspire to align the supply of and demand for science, scientists and stakeholders must work together from the outset to identify alignment and develop a working relationship founded on reciprocal communication. As Silka and Renault-Caragianes (2007) write, "if the community is invited in after researchers have determined the hypothesis, for example, there will be few opportunities for community knowledge to shape the cycle of research, and thus less likelihood that community members will benefit from the results'' (175). If researchers in higher 
education are to meet the demands for co-producing knowledge that may be used to solve on-the-ground problems, this study suggests that we must engage flexibly in collaborations, negotiate to meet the needs of project partners, and continuously assess partnership expectations and preferences so the partnership may evolve as partners' needs change. Although, as Polk (2014) discusses, co-producing knowledge in transdisciplinary partnerships does not, alone, mean that we are improving sustainability, partnerships help us, as a society, adapt to and learn within ongoing societal and environmental changes. To strengthen development, functioning, and deliverables of the partnerships, we must also discover new strategies for learning about and communicating within the partnership. 
Acknowledgments

Thank you to Dr. Bridie McGreavy for providing examples of how this research influenced her research collaborations. Portions of the manuscript were presented in a poster presentation at the 2012 Conference on Public Participation in Scientific Research in Portland, Oregon. This research was supported by the National Science Foundation award EPS-0904155 and Maine EPSCoR at the University of Maine. We thank our colleagues at the University of Maine's Senator George J. Mitchell Center for Sustainability Solutions for spearheading the research initiative that supported this collaborative work.

Compliance with ethical standards

This research study was approved by the University of Maine Institutional Review Board and complied with ethical standards for the treatment of human subjects. 
Figures

Figure 1 Conceptual model: stakeholder participation strategy preferences in community-university partnerships

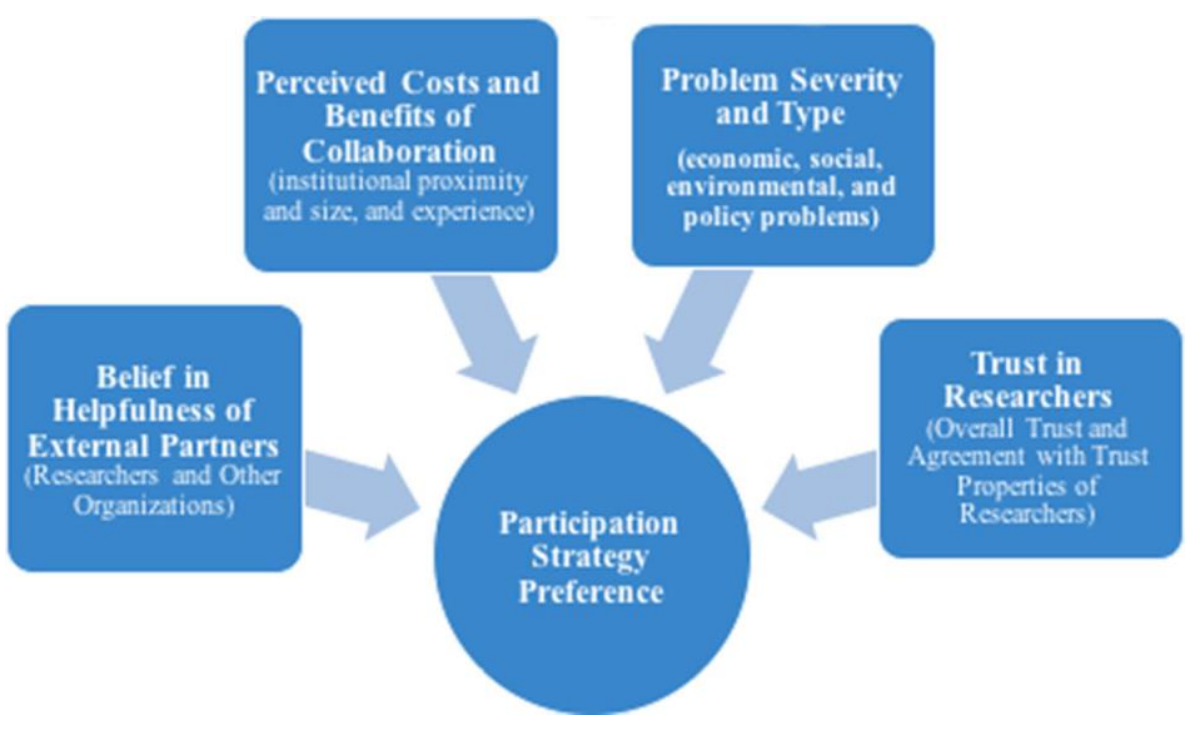


Table 1 Community-university research partnership strategy options

\begin{tabular}{|c|c|c|c|c|}
\hline Type of partnership & Problem identification & Research & Proposed solutions & Implementation \\
\hline Lead: university as lead partner & Univ. researchers & Univ. researchers & Univ. researchers & Local government \\
\hline $\begin{array}{l}\text { Consulting: university as } \\
\text { consulting partner }\end{array}$ & LGOs Univ. researchers & Univ. researchers & Univ. researchers & LGOs \\
\hline $\begin{array}{l}\text { Facilitate: university as } \\
\text { facilitating partner }\end{array}$ & LGOs Univ. researchers & Univ. researchers & LGOs Univ. researchers & LGOs \\
\hline Full: university as full partner & LGOs Univ. researchers & LGOs Univ. researchers & LGOs Univ. researchers & LGOs Univ. researchers \\
\hline
\end{tabular}


Table 2 Empirical model variables: descriptive statistics

\begin{tabular}{|c|c|c|c|}
\hline Variable name & Measurement & $\begin{array}{r}\text { Mean/ } \\
\%\end{array}$ & $\begin{array}{l}\text { Std. } \\
\text { dev. }\end{array}$ \\
\hline \multicolumn{4}{|l|}{ Preferred participation strategy } \\
\hline \multirow[t]{3}{*}{ Preferred strategy } & Consulting $=$ consulting strategy & 36.7 & \\
\hline & Facilitate $=$ facilitating strategy & 38.3 & \\
\hline & Full $=$ full strategy & 25.0 & \\
\hline \multicolumn{4}{|l|}{ Helpfulness of researchers } \\
\hline Researchers helpful_yes & Equals 1 if "yes" to question about potential assistance; else 0 & 0.33 & 0.47 \\
\hline Researchers helpful_not sure & Equals 1 if "not sure" to question about potential assistance; else 0 & 0.54 & 0.50 \\
\hline Researchers helpful_no ${ }^{\mathrm{a}}$ & Equals 1 if "no" to question about potential assistance; else 0 & 0.13 & 0.34 \\
\hline \multicolumn{4}{|l|}{ Helpfulness of other organizations } \\
\hline Others helpful_yes & Equals 1 if "yes" to question about potential assistance; else 0 & 0.38 & 0.49 \\
\hline Others helpful_not sure & Equals 1 if "not sure" to question about potential assistance; else 0 & 0.54 & 0.50 \\
\hline Others helpful_no ${ }^{\mathrm{b}}$ & Equals 1 if "no" to question about potential assistance; else 0 & 0.08 & 0.27 \\
\hline \multicolumn{4}{|c|}{ Perceived costs and benefits of collaboration } \\
\hline Municipality distance & Miles between municipality and closest university & 12.61 & 9.57 \\
\hline \multirow{2}{*}{$\begin{array}{l}\text { Municipality population } \\
\text { Experience }\end{array}$} & Population size (full-time residents) divided by 100 & 54.89 & 84.19 \\
\hline & $\begin{array}{l}\text { Equals } 1 \text { if participant had prior experience working with university } \\
\text { faculty, staff, or student researchers }\end{array}$ & 0.34 & 0.47 \\
\hline \multicolumn{4}{|l|}{ Problem severity and type } \\
\hline Economic problems & Equals the mean score across economic problems & 1.78 & 0.55 \\
\hline Social problems & Equals the mean score across social problems & 1.24 & 0.58 \\
\hline Environmental problems & Equals the mean score across environmental problems & 0.80 & 0.58 \\
\hline Policy problems & Equals the mean score across policy problems & 1.06 & 0.51 \\
\hline \multicolumn{4}{|l|}{ Trust in researchers } \\
\hline Low trust $\mathrm{c}^{\mathrm{c}}$ & $\begin{array}{l}\text { Equals } 1 \text { if "not at all, a little, or not sure" response about overall trust; } \\
\text { else } 0\end{array}$ & 0.31 & 0.46 \\
\hline Trust some & Equals 1 if "some" response about overall trust; else 0 & 0.28 & 0.45 \\
\hline Trust a lot & Equals 1 if "a lot" response about overall trust; else 0 & 0.41 & 0.49 \\
\hline \multicolumn{4}{|c|}{ Agreement with trust properties of researchers } \\
\hline $\begin{array}{l}\text { Trust properties about shared } \\
\text { interests/values }\end{array}$ & Mean score across value-related trust properties & 3.19 & 0.63 \\
\hline Trust properties about knowledge & Mean score across knowledge-related trust properties & 3.65 & 0.71 \\
\hline
\end{tabular}

$N=596$

a Researchers Helpful_no is the reference category in the discrete choice analysis

b Others Helpful_no is the reference category in the discrete choice analysis

${ }^{c}$ Low Trust is the reference category in the discrete choice analysis 
Figure 2 Predicted likelihood of choosing a specific participation strategy, by respondent experience with university researchers and their view of the helpfulness of the researchers. Based on the respondent: works in a municipality with a population of 5600 and 12.6 miles away from a university, perceives others as not helpful, all problem types are not a problem, trusts university researchers a lot and agrees that university researchers share their values and are knowledgeable.

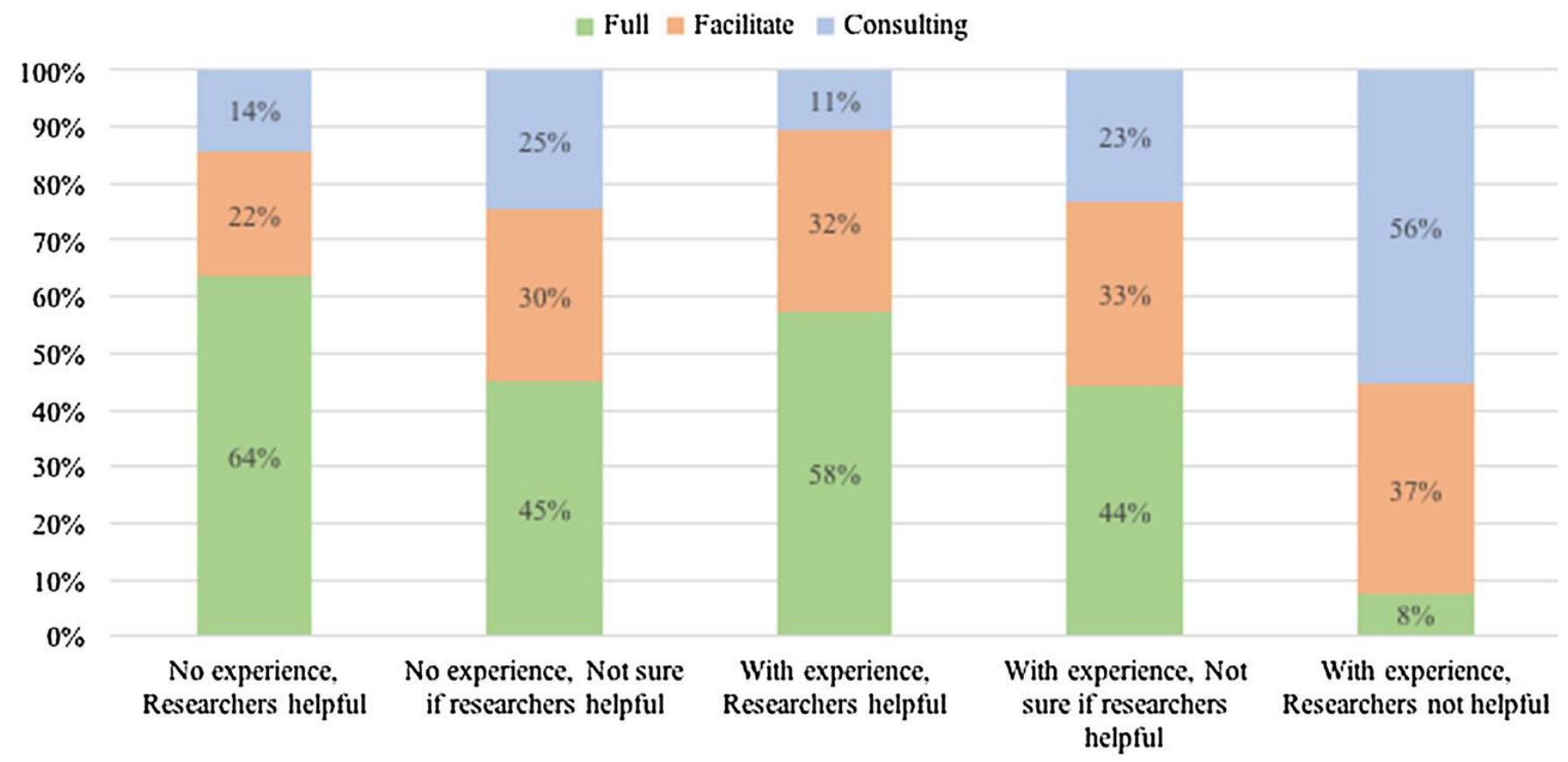


Figure $3 \mathrm{a}, \mathrm{b}$ Predicted likelihood of choosing a specific participation strategy, given respondent views of the helpfulness of the other researchers. Based on the respondent: works in a municipality with a population of 5600 and 12.6 miles away from a university, has no experience with university researchers and perceives them as not helpful, all problem types are not a problem, trusts university researchers $a$ lot and agrees that university researchers share their values and are knowledgeable.

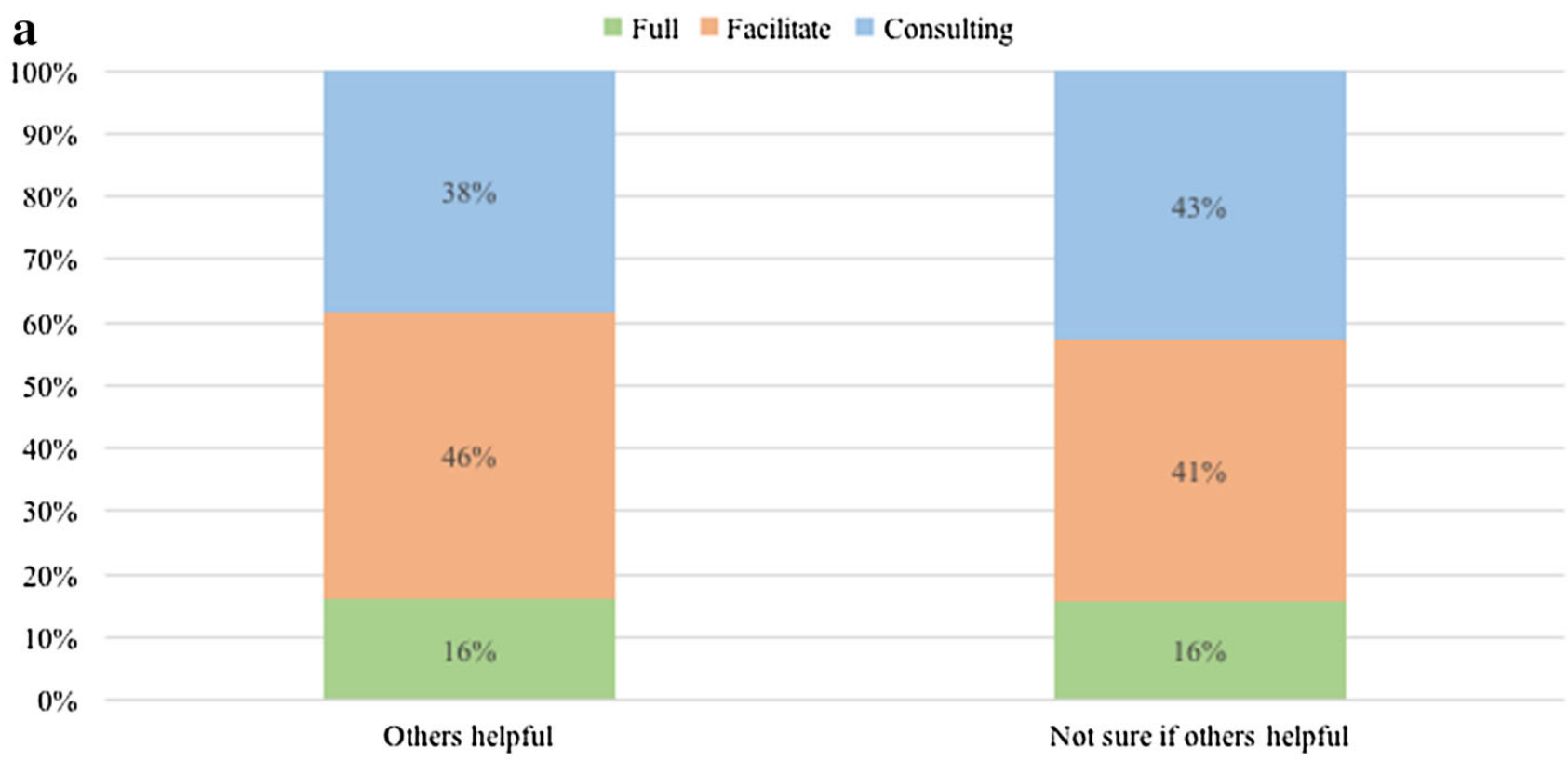

b Predicted likelihood of choosing a specific participation strategy, given that individual had experience with researchers and found them not helpful

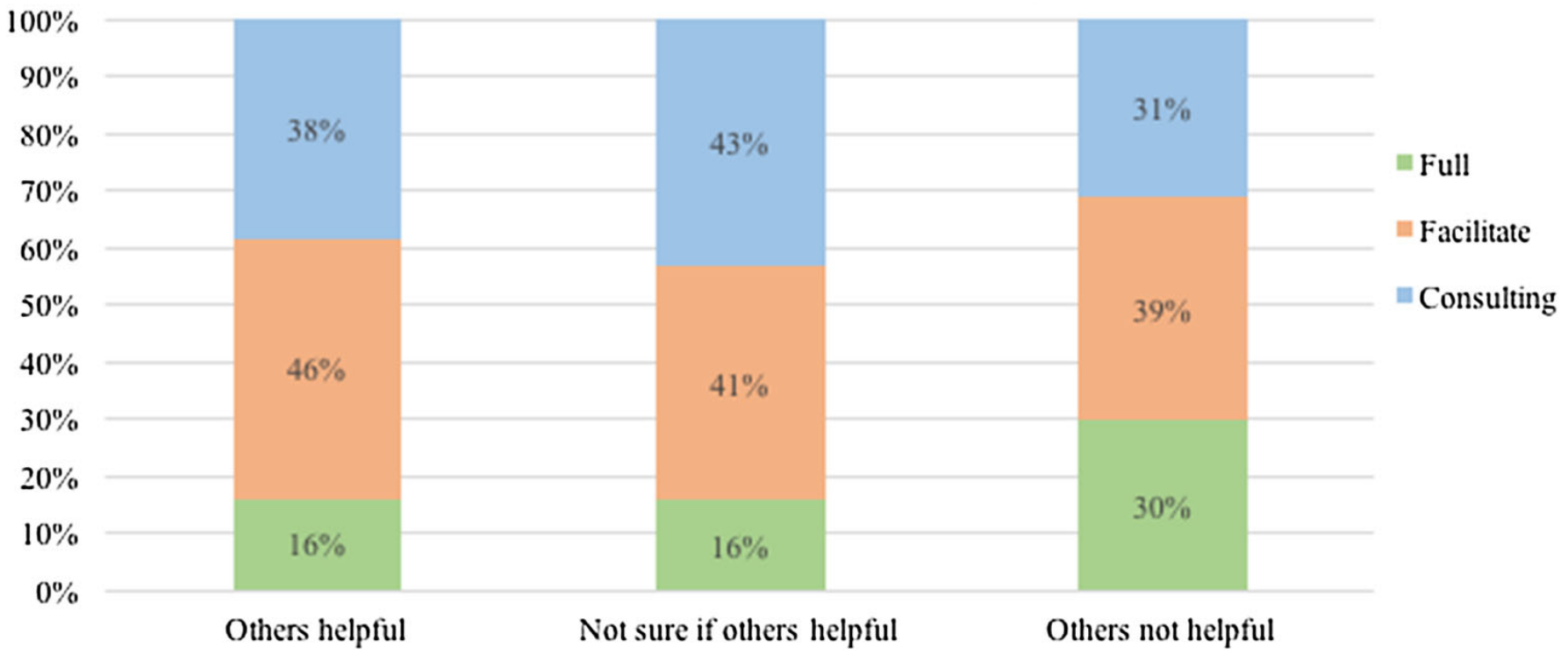


Figure 4 Predicted likelihood of choosing a specific participation strategy, given respondent views of the seriousness of different types of problems. Based on the respondent: works in a municipality with a population of 5600 and 12.6 miles away from a university, has no experience with university researchers and perceives them as not helpful, perceives others as not helpful, trusts university researchers a lot and agrees that university researchers share their values and are knowledgeable. Further, issues not a problem assumes all problem types are not a problem/debated, for all other results above, the issues that are a serious problem assumes all other problems are not a problem.

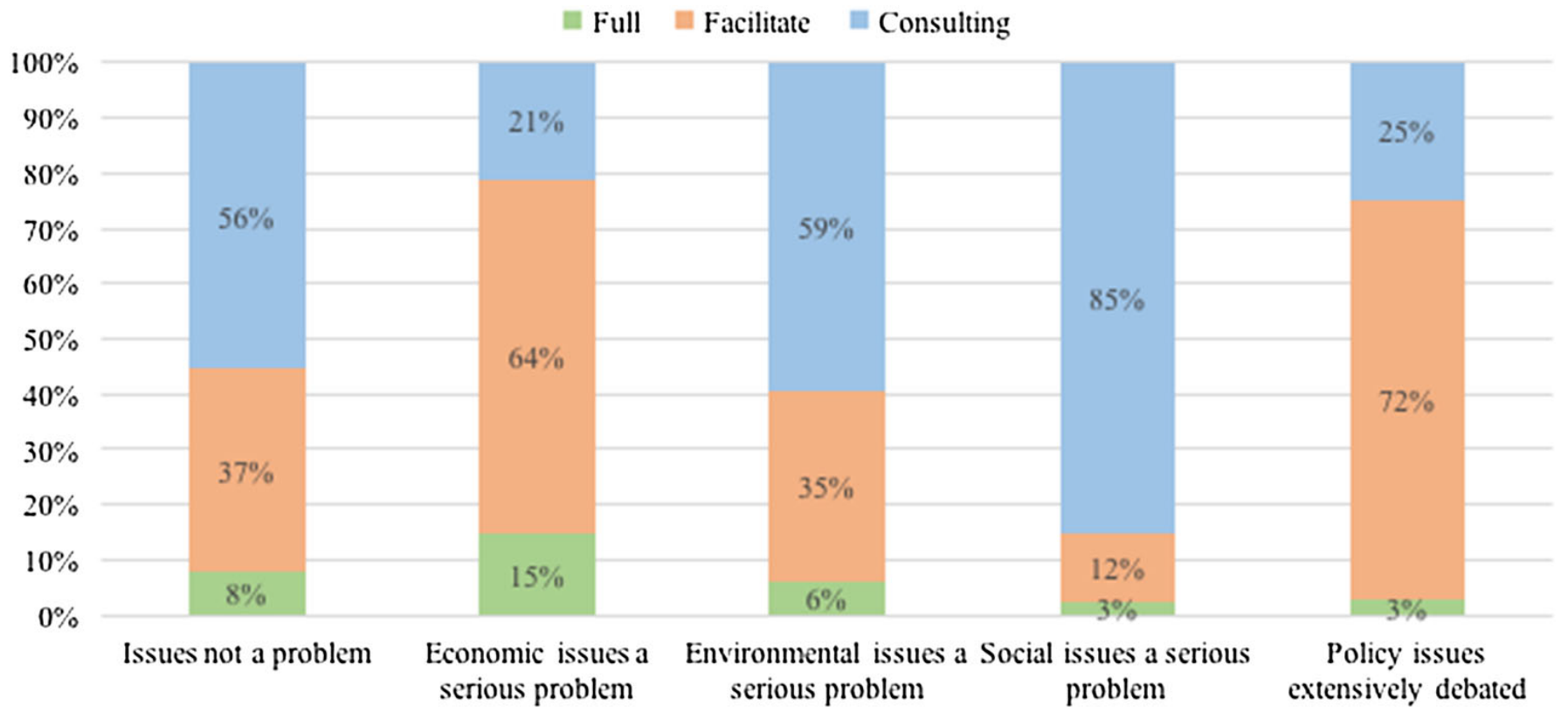


Figure 5 Predicted likelihood of choosing a specific participation strategy, by respondent level of general trust of university researchers. Based on the respondent: works in a municipality with a population of 5600 and 12.6 miles away from a university, has no experience with university researchers and perceives them as not helpful, all problem types are not a problem, and agrees that university researchers share their values and are knowledgeable.

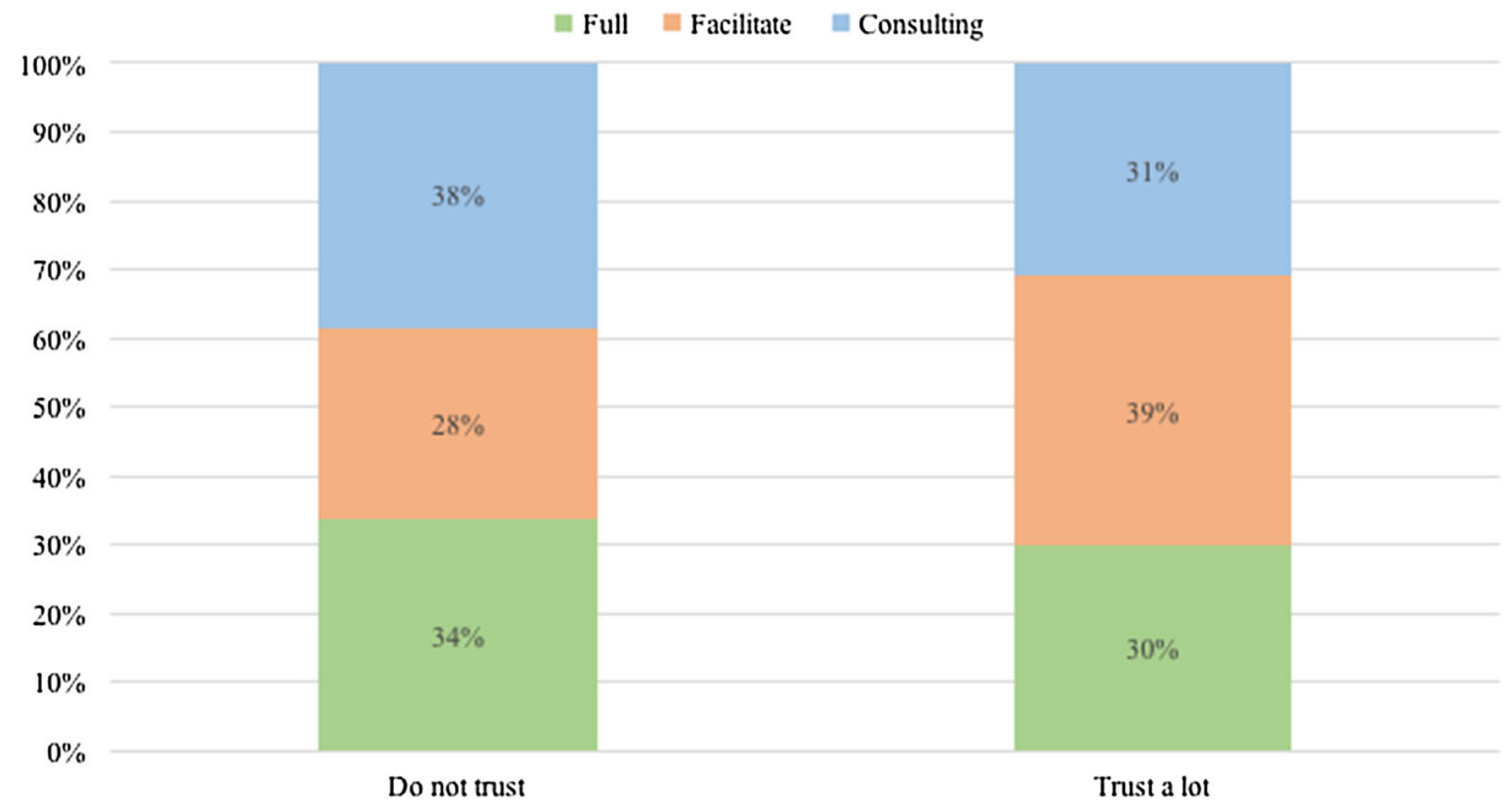


Figure 6 a, b Predicted likelihood of choosing a specific participation strategy, by respondent level of trust in university researchers sharing respondent values, or by respondent level of trust in university researchers technical knowledge. Based on the respondent: works in a municipality with a population of 5600 and 12.6 miles away from a university, has no experience with university researchers and perceives them as not helpful, all problem types are not a problem, and does not trust university researchers. Further, results related to: trust in values assumes trust in knowledge is low and trust in knowledge assumes trust in values is low.

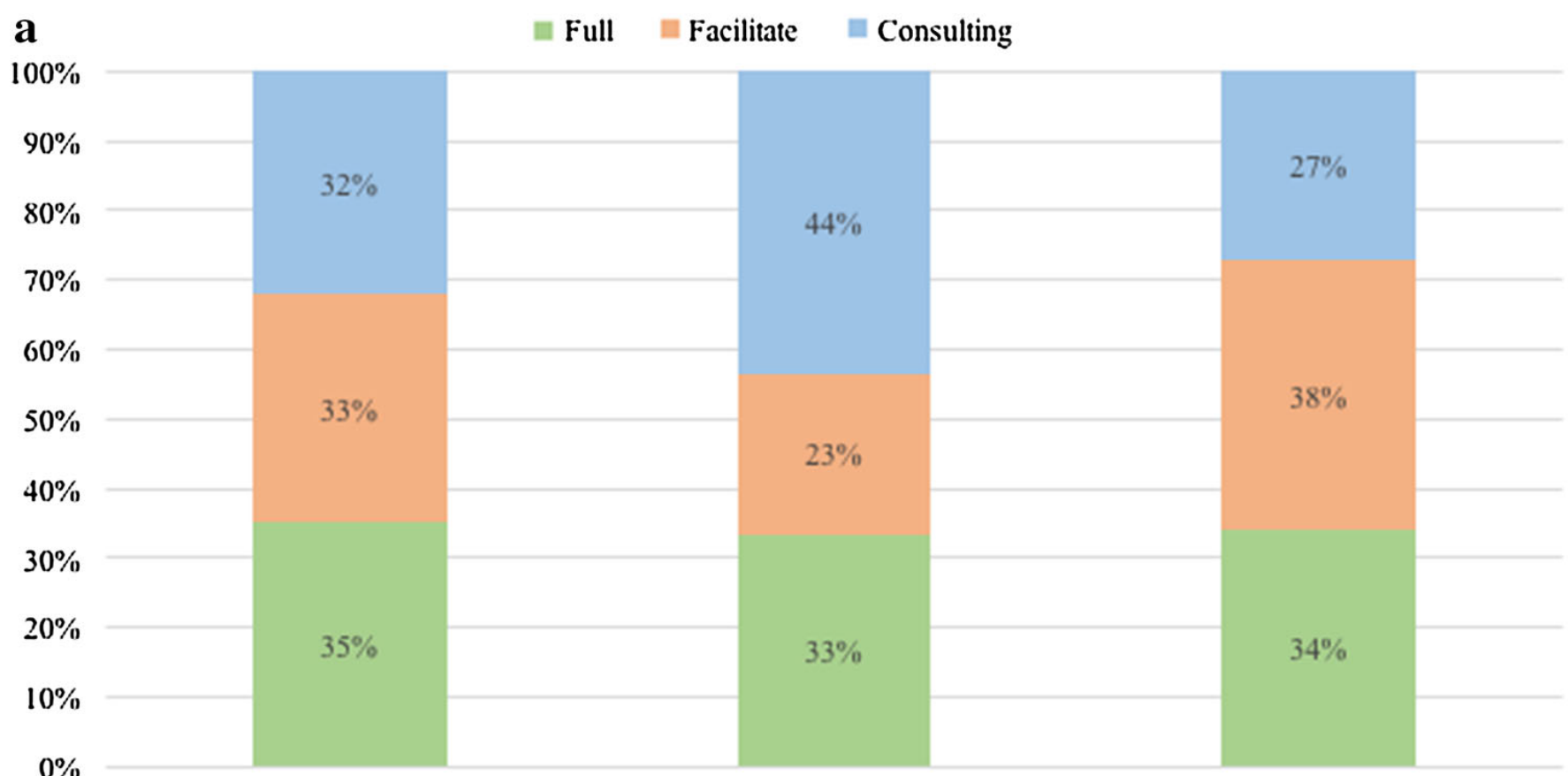

Low trust on shared valuies and technical knowledge
High trust on shared values only

Full $=$ Facilitate $\quad$ Consulting

b

$100 \%$

$90 \%$

$80 \%$

$70 \%$

$60 \%$

$50 \%$

$40 \%$

$30 \%$

$20 \%$

$10 \%$

$0 \%$

Low Trust based on shared Interests/Values
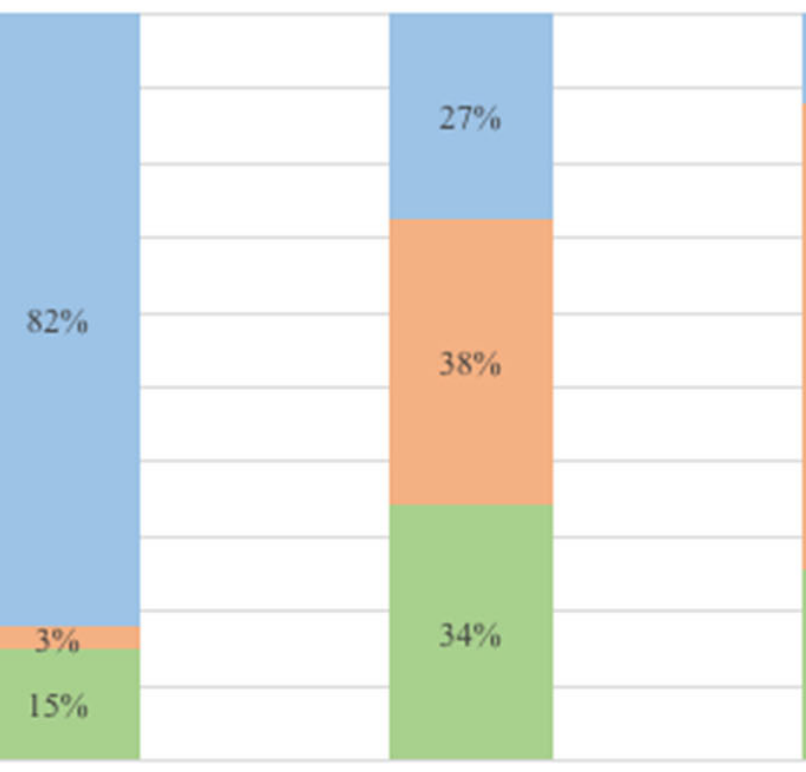

High trust on technical knowledge only

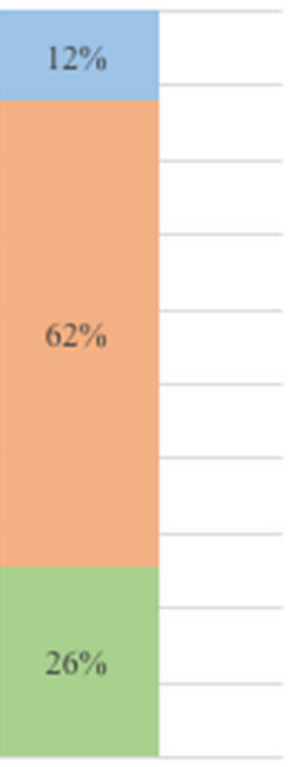

High Trust based on shared Low Trust based on Technical Interests/Values
High Trust based on Technical Knowledge 
Appendix A: Maine municipal official survey

Economic issues

How much do you consider each of the following to be a problem for your municipality? (Please check one box for each issue.) (Response Scale: Serious Problem-Not a Problem; allowed for responses of Not Sure and Not Applicable)

Declining property tax base

Declining job opportunities Poor business climate

Mismatch between skills of workforce and jobs

Lack of education and training opportunities for residents

Limited access to communication networks for residents and employers

Rising health care costs for residents and employers

Rising energy costs for residents and employers

Reductions in state funding (e.g. school subsidy, revenue sharing)

Declining transportation infrastructure.

Social issues

How much do you consider each of the following to be a problem for your municipality? (Please check one box for each issue.) (Response Scale: Serious Problem-Not a Problem; allowed for responses of Not Sure and Not Applicable)

Declining quality of public schools

Rising unemployment rate

Rising poverty rate

Increasing drug and alcohol abuse

Decreasing access to social services for elderly and low- income residents 
Decreasing recreation opportunities

Increasing crime rate

Increasing migration to your community

Changing ethnic and cultural diversity Decreasing access to health services

Increasing aging population (persons 65 or older)

Decreasing participation in community groups.

Environmental and natural resource issues

How much do you consider each of the following to be a problem for your municipality? (Please check one box for each issue.) (Response Scale: Serious Problem-Not a Problem; allowed for responses of Not Sure and Not Applicable)

Decreasing lake water quality

Decreasing river and stream water quality

Decreasing coastal water quality

Decreasing ground water quality

Decreasing air quality

Loss of forest land Loss of farm land

Loss of working waterfront

Decreasing public access to natural resource areas

Increasing risks of flooding

Increasing invasive insects and/or plants

Increasing traffic congestion

Changing climate.

Policy Issues

Public policy issues may generate debate in municipalities. How much debate have you seen on the following 
policy issues in your municipality? (Please check one box for each issue.) (Response Scale: Serious Debate-No

Debate; allowed for responses of Not Sure and Not Applicable)

Storm water regulations

Shorebird habitat regulations

Land use planning/zoning regulations

Shoreland zoning regulations

Siting of commercial wind farms

Siting of residential wind energy systems

Siting of communication towers

Siting of energy transmission lines FEMA Flood Zone Maps

Regionalization

Do you think researchers from the University of Maine System could be of assistance in resolving some of your municipality's issues? (Please check one box.) (Response Options: yes, no, not sure)

Do you think other organizations could be of assistance in resolving some of your municipality's issues? (Please check one box.) (Response Options: yes, no, not sure)

Since you began your position, has your municipality worked with any researchers from a university or college in Maine? (Please check one box for each category.) (Response Options: yes, no, not sure)

How much do you trust researchers (faculty/staff) from the University of Maine System? (Please check one box.)

(Response Scale: Not at all-A lot; allowed for response of Not Sure)

To what extent do you disagree or agree with the following statements: "I trust researchers (faculty/staff) from the University of Maine System because they .' (Please check one box for each statement.) (Response Scale:

Strongly disagree-Strongly agree)

Provide scientific information

Provide unbiased information

Provide reliable information

Use my input

Respect diverse opinions 
Present useful information

Care about my community

Focus on issues I want to know about

Have high technical competence

Share my values

Community-University partnerships are structured in many ways. We are interested in your opinion about four alternative strategies for community-university partnerships. The alternatives differ according to how municipalities and university researchers share responsibilities.

\begin{tabular}{|c|c|c|c|c|}
\hline $\begin{array}{l}\text { Type of } \\
\text { partnership }\end{array}$ & $\begin{array}{l}\text { Problem } \\
\text { identification }\end{array}$ & Research & $\begin{array}{l}\text { Proposed } \\
\text { solutions }\end{array}$ & $\begin{array}{l}\text { Implemen- } \\
\text { tation }\end{array}$ \\
\hline $\begin{array}{l}\text { A. University| } \\
\text { as lead } \\
\text { partner }\end{array}$ & $\begin{array}{l}\text { Univ. } \\
\text { researchers }\end{array}$ & $\begin{array}{l}\text { Univ. } \\
\text { researchers }\end{array}$ & $\begin{array}{l}\text { Univ. } \\
\text { researchers }\end{array}$ & $\begin{array}{r}\text { Municipal } \\
\text { officials }\end{array}$ \\
\hline $\begin{array}{l}\text { B. University } \\
\text { as } \\
\text { consulting } \\
\text { partner }\end{array}$ & $\begin{array}{l}\text { Univ. } \\
\text { researchers }\end{array}$ & $\begin{array}{l}\text { Univ. } \\
\text { researchers }\end{array}$ & $\begin{array}{l}\text { Univ. } \\
\text { researchers }\end{array}$ & $\begin{array}{r}\text { Municipal } \\
\text { officials }\end{array}$ \\
\hline $\begin{array}{l}\text { C. University } \\
\text { as } \\
\text { facilitating } \\
\text { partner }\end{array}$ & $\begin{array}{l}\text { Municipal } \\
\text { officials } \\
\text { Univ. } \\
\text { researchers }\end{array}$ & $\begin{array}{l}\text { Univ. } \\
\text { researchers }\end{array}$ & $\begin{array}{l}\text { Municipal } \\
\text { officials } \\
\text { Univ. } \\
\text { researchers }\end{array}$ & $\begin{array}{r}\text { Municipal } \\
\text { officials }\end{array}$ \\
\hline $\begin{array}{l}\text { D. University } \\
\text { as full } \\
\text { partner }\end{array}$ & $\begin{array}{l}\text { Municipal } \\
\text { officials } \\
\text { Univ. } \\
\text { researchers }\end{array}$ & $\begin{array}{l}\text { Municipal } \\
\text { officials } \\
\text { Univ. } \\
\text { researchers }\end{array}$ & $\begin{array}{l}\text { Municipal } \\
\text { officials } \\
\text { Univ. } \\
\text { researchers }\end{array}$ & $\begin{array}{l}\text { Municipal } \\
\text { officials } \\
\text { Univ. } \\
\text { researchers }\end{array}$ \\
\hline
\end{tabular}

Participation strategy you most prefer: (A, B, C or D)

(write-in one letter from the list above). 
Appendix B: Discrete choice analysis results: participation strategy preferences

\begin{tabular}{lll}
\hline Variable & $\begin{array}{l}\text { Coefficient } \\
\text { reference }=\text { consult }\end{array}$ & $\begin{array}{l}\text { Standard } \\
\text { error }\end{array}$ \\
\hline Experience-facilitate & -0.652 & 0.583 \\
Experience-full & $-1.938^{*}$ & 1.128 \\
Researchers helpful_yes-Facilitate & $0.201^{\mathrm{a}}$ & 0.491 \\
Researchers helpful_yes-Full & $1.530^{* * *^{\mathrm{a}}}$ & 0.607 \\
$\begin{array}{l}\text { Researchers helpful_not sure- } \\
\text { facilitate }\end{array}$ & $-0.030^{\mathrm{a}}$ & 0.445 \\
$\begin{array}{l}\text { Researchers helpful_not sure-Full } \\
\text { Researchers helpful_yes x }\end{array}$ & $0.642^{\mathrm{a}}$ & 0.570 \\
$\quad$ experience-facilitate & $1.288^{*}$ & 0.693 \\
$\begin{array}{l}\text { Researchers helpful_yes x } \\
\text { experience-full }\end{array}$ & $2.119^{*}$ & 1.189 \\
$\begin{array}{l}\text { Researchers helpful_not sure x } \\
\text { experience-facilitate }\end{array}$ & 0.783 & \\
Researchers helpful_not sure x & $1.975^{*}$ & 0.632 \\
$\quad \begin{array}{l}\text { experience-full } \\
\text { Others helpful_yes-facilitate }\end{array}$ & $-0.067^{\mathrm{b}}$ & 1.163 \\
$\begin{array}{l}\text { Others helpful_yes-full } \\
\text { Others helpful_not sure-facilitate }\end{array}$ & $-0.828^{\mathrm{b}}$ & 0.482 \\
$\begin{array}{l}\text { Others Helpful_not sure-Full } \\
\text { Distance from University/College- } \\
\text { facilitate }\end{array}$ & $-0.964^{\mathrm{b}}$ & 0.599 \\
$\begin{array}{l}\text { Distance from University/College- } \\
\text { full }\end{array}$ & -0.003 & 0.487 \\
\begin{tabular}{l} 
Municipality population-facilitate \\
\hline
\end{tabular} & 0.001 & 0.597 \\
\hline
\end{tabular}




\begin{tabular}{lcl}
\hline Variable & $\begin{array}{l}\text { Coefficient } \\
\text { reference }=\text { consult }\end{array}$ & $\begin{array}{l}\text { Standard } \\
\text { error }\end{array}$ \\
\hline Municipality population-full & 0.002 & 0.002 \\
Economic problems-facilitate & $0.508^{* *}$ & 0.224 \\
Economic problems-full & $0.536^{* *}$ & 0.249 \\
Environmental problems-facilitate & -0.043 & 0.195 \\
Environmental problems-full & -0.089 & 0.222 \\
Social problems-facilitate & $-0.506^{* *}$ & 0.238 \\
Social problems-full & $-0.514^{* *}$ & 0.262 \\
Policy problems-facilitate & $0.495^{* *}$ & 0.204 \\
Policy problems-full & -0.065 & 0.234 \\
Trust some-facilitate & $0.175^{\mathrm{c}}$ & 0.267 \\
Trust some-full & $-0.077^{\mathrm{c}}$ & 0.295 \\
Trust a lot-facilitate & $0.559^{\mathrm{c}}$ & 0.287 \\
Trust a lot-full & $0.095^{\mathrm{c}}$ & 0.318 \\
Trust properties about & $-0.660^{* * *}$ & 0.196 \\
interests/values-facilitate & & \\
Trust properties about & -0.359 & 0.221 \\
interests/values-full & & \\
Trust properties about technical & $0.326^{*}$ & 0.189 \\
knowledge-facilitate & & 0.213 \\
Trust properties about technical & 0.131 & \\
knowledge-full & & \\
\hline$N=596$, & & \\
\hline
\end{tabular}

$N=596, \chi_{d f=38}=95.32, p<0.001$

$* p<0.1 ; * * p<0.05 ; * * * p<0.01$

a Researchers helpful_no is the reference category

b Others helpful_no is the reference category

${ }^{c}$ Low Trust is the reference category 


\section{References}

Allen IE, Seaman CA (2007) Likert scales and data analyses. Qual Prog 40(7):64-65

Barreteau O, Bots P, Daniell K (2010) A framework for clarifying participation in participatory research to prevent its rejection for the wrong reasons. Ecol Soc 15(2):1

Bell K, Lindenfeld L, Speers A, Teisl M, Leahy J (2013) Creating opportunities for improving lake-focused stakeholder engagement: knowledge-action systems, pro-environment behaviour and sustainable lake management. Lakes Reserv 18(1):5-14. doi:10.1111/lre.12018

Cash DW, Clark WC, Alcock F, Dickson NM, Eckley N, Guston DH, Mitchell RB (2003) Knowledge systems for sustainable development. Proc Natl Acad Sci 100(14):8086-8091. doi:10.1073/ pnas.1231332100

Cash DW, Borck JC, Patt AG (2006) Countering the loading-dock approach to linking science and decision making comparative analysis of El Niño/Southern Oscillation (ENSO) forecasting systems. Sci Technol Human Values 31(4):465-494. doi:10. 1177/0162243906287547

Crona BL, Parker JN (2012) Learning in support of governance: theories, methods, and a framework to assess how bridging organizations contribute to adaptive resource governance. Ecol Soc 17(1):32. doi:10.5751/ES04534-170132research in the sustainable management of freshwater ecosystems. Freshw Biol 55(1):258269. doi:10.1111/j.1365-2427. 2009.02370.x

Ho“ppner C, Frick J, Buchecker M (2007) Assessing psycho-social effects of participatory landscape planning. Landsc Urban Plann 83(2):196-207. doi:10.1016/j.landurbplan.2007.04.005

Hutchins K, Lindenfeld L, Bell K, Leahy J, Silka L (2013) Strengthening knowledge co-production capacity: examining interest in community-university partnerships. Sustainability 5(9):3744-3770. doi:10.3390/su5093744

Israel BA, Schulz AJ, Parker EA, Becker AB (1998) Review of community-based research: assessing partnership approaches to improve public health. Annu Rev Public Health 19(1):173-202. doi:10.1146/annurev.publhealth.19.1.173

Kauffman J (2014) Promoting integration and cooperation for sustainability views from the symposium held at UNESCO headquarters September 19, 2013. Sustain Sci 9(4):419-430. doi:10.1007/s11625-014-0255-7 
Kauffman J, Arico S (2014) New directions in sustainability science: promoting integration and cooperation. Sustain Sci 9(4):413-418. doi:10.1007/s11625-014-0259-3

Kueffer C, Underwood E, Hirsch Hadorn G, Holderegger R, Lehning M, Pohl C, Edwards P (2012) Enabling effective problem- oriented research for sustainable development. Ecol Soc 17(4):8

Label Request Form (2016) Maine municipal association. http://www. memun.org/public/market/labels2.htm. Accessed 31 July 2013

Lang DJ, Wiek A, Bergmann M, Stauffacher M, Martens P, Moll P, Thomas CJ (2012) Transdisciplinary research in sustainability science: practice, principles, and challenges. Sustain Sci 7(1):25-43. doi:10.1007/s11625011-0149-x

Leahy JE, Anderson DH (2008) Trust factors in community—water resource management agency relationships. Landsc Urban Plan 87(2):100-107. doi:10.1016/j.landurbplan.2008.05.004

Leahy J, Lindenfeld L (2013) Linking knowledge with action: applied social science considerations to improve woody bioenergy research and development effectiveness. In: Jacobson Michael, Ciolkosz Daniel (eds) Wood-based energy in the northern forests. Springer, New York, pp 209-217

Lubell M (2004) Collaborative watershed management: a view from the grassroots. Policy Stud J 32(3):341-361. doi:10.1111/j.1541- 0072.2004.00069.x

Lubell M (2005) Do watershed partnerships enhance beliefs con- ducive to collective action? In: Sabatier PA, Focht W, Lubell M, Trachtenberg Z, Vedlitz A, Matlock M (eds) Swimming upstream: collaborative approaches to watershed management. MIT Press, Cambridge, pp 201-232

Lubell M (2007) Familiarity breeds trust: collective action in a policy domain. J Polit 69(1):237-250

Lubell M, Schneider M, Scholz JT, Mete M (2002) Watershed partnerships and the emergence of collective action institutions. Am J Polit Sci 46(1):148-163

Lyons P, Leahy J, Lindenfeld L, Silka L (2014) Knowledge to action: implicit knowledge production models held among forest science researchers. Soc Nat Resour 27(5):459-474. doi:10.1080/ 08941920.2013.861552

Matson P (2009) The sustainability transition. Issues Sci Technol 25(4):39-42

McGreavy B, Lindenfeld L, Bieluch KH, Silka L, Leahy J, Zoellick B (2015) Communication and sustainability science teams as complex systems. Ecol Soc 20(1):2. doi:10.5751/ES-06644- 200102

McLarty D, Davis N, Gellers J, Nasrollahi N, Altenbernd E (2014) Sisters in sustainability: municipal partnerships 
for social, environmental, and economic growth. Sustain Sci 9:277-292. doi:10.1007/s11625- 014-0248-6

Muñoz-Erickson TA, Cutts BB, Larson EK, Darby KJ, Neff M, Wutich A, Bolin B (2010) Spanning boundaries in an Arizona watershed partnership: information networks as tools for entrenchment or ties for collaboration? Ecol Soc 15(3):22

Nyden P (2005) The challenges and opportunities of engaged scholarship. In: Silka L (ed) Scholarship in action. US Depart- ment of Housing and Urban Development, Washington D.C., United States of America, pp 910

Oliver DM, Fish RD, Winter M, Hodgson CJ, Heathwaite AL, Chadwick DR (2012) Valuing local knowledge as a source of expert data: farmer engagement and the design of decision support systems. Environ Model Softw 36:76-85. doi:10.1016/j. envsoft.2011.09.013

Peterson JC (2010) CBPR in Indian country: tensions and implications for health communication. Health Commun 25(1):50-60. doi:10. 1080/10410230903473524

Pettersson C, Lindeń-Boström M, Eriksson C (2009) Reasons for non-participation in a parental program concerning underage drinking: a mixed-method study. BMC Public Health 9:1-19. doi:10. 1186/14712458-9-1

Polk M (2014) Achieving the promise of transdisciplinarity: a critical exploration of the relationship between transdisciplinary research and societal problem solving. Sustain Sci 9:1-13. doi:10.1007/s11625-014$0247-7$

Prober SM, O’Connor MH, Walsh FJ (2011) Australian Aboriginal peoples' seasonal knowledge: a potential basis for shared understanding in environmental management. Ecol Soc 16(2):12

Reed MS, Evely AC, Cundill G, Fazey I, Glass J, Laing A, Newig J, Parrish B, Prell C, Raymond C, Stringer LC (2010) What is social learning? Ecol Soc 15(4):r1

Reich SM, Reich JA (2006) Cultural competence in interdisciplinary collaborations: a method for respecting diversity in research partnerships. Am J Commun Psychol 38(1-2):51-62. doi:10. 1007/s10464-0069064-1

Robinson J (2008) Being undisciplined: transgressions and intersections in academia and beyond. Futures 40(1):70-86. doi:10.1016/ j.futures.2007.06.007 
SAS Institute Inc. (2012) SAS/ETS® 12.1 user's guide. SAS Institute

Inc., Cary

Schneider F, Rist S (2014) Envisioning sustainable water futures in a transdisciplinary learning process:

combining normative, explorative, and participatory scenario approaches. Sustain Sci 9:463-481. doi:10.1007/s11625-013-0232-6

Schusler TM, Decker DJ, Pfeffer MJ (2003) Social learning for collaborative natural resource management. Soc Nat Resour 16(4):309-326. doi:10.1080/08941920390178874

Shirk JL, Ballard HL, Wilderman CC, Phillips T, Wiggins A, Jordan R, McCallie E, Minarchek M, Lewenstein BV, Krasny ME, Bonney R (2012) Public participation in scientific research: a framework for deliberate design. Ecol Soc 17(2):29

Silka L, Renault-Caragianes P (2007) Community-university research partnerships: devising a model for ethical engagement. J High Educ Outreach Engagem 11(2):171-183

Silka L, Cleghorn GD, Grullón M, Tellez T (2008) Creating community-based participatory research in a diverse community: a case study. J Empir Res Human Res Ethics 3(2):5-16. doi:10. 1525/jer.2008.3.2.5

Smith J, Leahy J, Anderson D, Davenport M (2013a) Community/ agency trust and public involvement in resource planning. Soc Nat Resour 26(4):452-471. doi:10.1080/08941920.2012.678465

Smith J, Leahy J, Anderson D, Davenport M (2013b) Community/ agency trust: a measurement instrument. Soc Nat Resour 26(4):472-477. doi:10.1080/08941920.2012.742606

Stauffacher M, Flu“eler T, Kru“tli P, Scholz RW (2008) Analytic and dynamic approach to collaboration: a transdisciplinary case study on sustainable landscape development in a Swiss prealpine region. Syst Pract Action Res 21(6):409-422. doi:10.1007/ s11213-008-9107-7

Thornton T, Leahy J (2012) Trust in citizen science research: a case study of the groundwater education through water evaluation and testing program. JAWRA J Am Water Resour Assoc 48(5):1032-1040. doi:10.1111/j.1752-1688.2012.00670.x

Tompkins EL, Adger WN (2004) Does adaptive management of natural resources enhance resilience to climate change? Ecol Soc 9(2):10

van der Leeuw S, Wiek A, Harlow J, Buizer J (2012) How much time do we have? Urgency and rhetoric in sustainability science. 
Sustain Sci 7(1):115-120. doi:10.1007/s11625-011-0153-1

van Kerkhoff L (2008) Making a difference: science, action and integrated environmental research. Sense Publishers, Rotterdam

van Kerkhoff L (2014) Developing integrative research for sustain- ability science through a complexity principles-based approach. Sustain Sci 9(2):143-155. doi:10.1007/s11625-013-0203-y

Vaske JJ (2008) Survey research and analysis: applications in parks, recreation and human dimensions. Venture Publishing, State College

Walter AI, Helgenberger S, Wiek A, Scholz RW (2007) Measuring societal effects of transdisciplinary research projects: design and application of an evaluation method. Eval Prog Plan 30(4):325-338. doi:10.1016/j.evalprogplan.2007.08.002

Wiek A, Ness B, Schweizer-Ries P, Brand FS, Farioli F (2012) From complex systems analysis to transformational change: a comparative appraisal of sustainability science projects. Sustain Sci 7(1):5-24. doi:10.1007/s11625-011-0148-y 